\title{
More women with the pelvic girdle syndrome than with other pelvic pain during pregnancy had pelvic pain 2 years after delivery
}

\author{
Albert H, Godskesen M, Westergaard J. Prognosis in four syndromes of pregnancy-related pelvic pain. Acta Obstet Gynecol \\ Scand 2001 Jun;80:505-10.

\section{QUESTION: In women with pregnancy-related pelvic joint pain, what are the predictors and prevalence of long term symptoms?}

Sources of funding:
Health Insurance
Foundation; Funen
County Board of
Prevention; Danish
Physiotherapist
Research Foundation;
Danish Manual
Therapy Group.
For correspondence:
Ms H Albert,
Department of
Physiotherapy, Odense
University Hospital,
Sdr. Boulevard, 5000
Odense C., Denmark.
Fax +45 6613 2854.

\section{COMMENTARY}

Back pain and pelvic pain affect almost $50 \%$ of pregnant women. ${ }^{1}$ The study by Albert et al followed women with pelvic pain for longer than any previous study. The study did not compare lumbar back pain with pelvic pain, which is a pity because we lack good prognostic information on such women. The study distinguishes pelvic pain from lumbar back pain and describes tests that may help to differentiate sites of pelvic pain. The authors describe these as "objective" tests. I am unhappy about this term because the tests rely on a subjective response about pain. Nonetheless, the study was able to distinguish different sites of pain, which is important because it allows better prognostic information. In the future, healthcare workers caring for pregnant women should examine those with back and pelvic pain more carefully. The good news is that we can tell women with pubic symphysis pain that they are almost certain to be free of pain 6 months after delivery. I share the authors' unease about using the term symphysiolysis, which implies that the joint is dissolving - a distressing image to conjure up. Symphysial pain would be a better term.

This study showed that for the $6.6 \%$ of pregnant women (of the 1789 women who were booked for delivery at the study site) who had symphysial and sacroiliac joint pains (pelvic girdle pain) at baseline, $21 \%$ will still have pain 2 years after giving birth. Determining how to treat women with such pain is not straightforward because we lack good evidence about treatments. Trochanteric belts ${ }^{2}$ and acupuncture may help. ${ }^{3}$ A Cochrane review on preventing and treating backache in pregnancy will be updated next year. ${ }^{4}$ Gavin Young, MA, MB, BS The Surgery Penrith, Cumbria, UK

1 Mantle MJ, Greenwood RM, Currey HL. Backache in pregnancy. Rheumatol Rehabil 1977;16:95-101.

2 Berg G, Hammar M, Moller-Nielsen J, et al. Low back pain during pregnancy. Obstet Gynecol 1988;71:71-5.

3 Wedenberg K, Moen B, Norling A. A prospective randomized study comparing acupuncture with physiotherapy for low-back and pelvic pain in pregnancy. Acta Obstet Gynecol Scand 2000;79:331-5.

4 Young G, Jewell D. Interventions for preventing and treating backache in pregnancy. Cochrane Database Syst Rev 2001;(3):CD001139. sided sacroiliac syndrome $(\mathrm{n}=120$; daily pain from both sacroiliac joints); or miscellaneous $(n=31$; daily pain in $\geqslant$ 1 pelvic joint, but inconsistent findings from the history). Patients with no objective evidence of pelvic joint pain or those with the same or lower intensity of pelvic joint or low back pain as before the pregnancy were excluded $(\mathrm{n}=1384)$. Follow up was $84 \%$.

\section{Assessment of prognostic factors}

Epidemiological and obstetric background data and pain history obtained from a questionnaire and physical examination (pain tests and index of mobility). Demographic data (age, education, and employment history) were also assessed.

\section{Main outcome measures}

Pelvic pain $(\geqslant 1$ positive pain test result for $\geqslant 1$ pelvic joint). Women were examined at 1, 3, 6, 12, 18, and 24 months after delivery or until symptoms disappeared whichever occurred first. All women seen at 6 months of follow up were examined 6 months later.

\section{Main results}

Continued pelvic joint pain at 2 years occurred in 21 of the 100 women $(21 \%)$ with the pelvic girdle syndrome who were followed; 0 of $33(0 \%)$ with symphysiolysis; 1 of $82(1.2 \%)$ with the 1 -sided sacroiliac syndrome; 5 of $99(5.1 \%)$ with the double-sided sacroiliac syndrome; and 2 of $27(7.4 \%)$ with miscellaneous joint pain at baseline. No women with symphysiolysis had joint pain at 6 months after delivery. Prognostic factors associated with pelvic joint pain 2 years after delivery in women with the pelvic girdle syndrome were $\geqslant 16$ positive responses on objective pain tests (relative risk [RR] 10.7); low index of mobility ( $\leqslant 320$; RR 3.9$)$; no education (RR 2.3); multiparity (RR 2.0); older age ( $\geqslant 29 \mathrm{y}$; RR 1.9); and high intensity of pain $(\geqslant 6$ on a visual analog scale; RR 1.6). No prognostic indicators existed for the other groups.

\section{Conclusions}

Among women with pregnancy-related joint pain, more women with the pelvic girdle syndrome had pelvic pain at 2 years after delivery than did women with other pelvic pain. Women with symphysiolysis had no joint pain 6 months after delivery. 